\title{
Conditioning of disused Ra-226 radioactive sealed sources in Egypt
}

\author{
M.A. Hasan, Y.T. Selim, Y.F. Lasheen ${ }^{\mathrm{a}}$ and T. El-Zakla \\ Hot Labs \& Waste Management Center, Atomic Energy Authority, 3 Ahmed El-Zomor St., El-Zohour District, Naser City, 11787, Cairo, Egypt.
}

Received 11 August 2013 - Accepted 22 April 2014

\begin{abstract}
The present work describes the technical information on issues associated with the management of disused $\mathrm{Ra}-226$ radioactive sources. The different settings needed to condition these sources in stainless steel capsules, working area setup, packaging preparation, Ra-226 source characterization, capsule welding, leakage test and data information are completely described. The radium sources addressed in the present work are mainly those which have been used in medicine and for industrial applications, in the form of sealed radiation sources. In Egypt hospitals are among the largest users of sealed radium radioactive sources which are mostly used for brachytherapy. The inventory of radium sources in large hospitals could be in the hundreds. There is a real risk that sources may be lost or mishandled, if very restricted procedures are not followed. An additional problem with these sources is that they are often leaking, due to internal overpressure. The small size of the sources, portability and high apparent value (due to the materials of encapsulation) increase the risk of theft.
\end{abstract}

Keywords: Ra-226 / sealed sources / conditioning / waste management

\section{Introduction}

According to the law No. 7/2010, the Egyptian atomic energy authority represented by the Hot Laboratories \& Waste Management Center, HLWMC (centralized waste facility) has the responsibility of collecting, conditioning, storing and disposing of all types of radioactive waste from all Egyptian territory including spent radioactive sealed sources (SRSSs). Sealed Ra-226 radioactive sources have been widely used in Egypt for several decades for several aspects, in medicine, industry, research and the military. According to the IAEA, member states were requested to stop the utilization of Ra-226 sealed sources because of the longterm effect of radon (radium's daughter) gas on humans and the environment in cases where Ra-226 containers were cracked or leaked. In order to guarantee the protection of man and the environment, the unfavorable radiological characteristics of Ra-226 sources required special conditioning techniques that resulted in a safe containment from both radiological and physical security points of view (Punnachaiya et al., 2006). The dose assessment and working time during the conditioning process are controlled according to the IAEA effective occupational dose limit of $2000 \mathrm{mR} /$ year (8 mR/day) (IAEA, 1996a).

Ra-226 is an alpha emitter with a half-life of -1600 years. It is generally believed that due to the specific activity of the

\footnotetext{
a yasser202000@yahoo.com
}

sources and the half-life of Ra-226, final disposal in a suitable geological repository is necessary. Since such a repository is not easy to license, and probably needs a long time to be in operation, it is necessary to conceive a longterm interim storage facility for this type of radioactive waste until such time as a suitable final solution becomes available. The radioactive characteristics of Ra-226 and its daughters, particularly the gas Rn-222, necessitate that radium sources are suitably conditioned before interim storage. The solution chosen for conditioning should take into account that acceptance criteria concerning waste packages for geological disposal have not yet been established. Consequently, techniques developed for re-encapsulation of radium sources must avoid causing difficulties for later management. The conditioning process should follow the IAEA international standards for conditioning of disused Ra-226 sealed sources (IAEA, 1996b).

\section{Working area preparation}

Before starting conditioning of Ra-226 disused sealed radioactive sources, a working area should be set up to insure safe operation. As in Figure 1, a shielded working area with lead glass and lead cubes is prepared to protect workers during the conditioning operation. A tray lined with a plastic sheet and white paper is used for the Ra-226 sources that will be conditioned to insure recognizing the sources and facilitating 


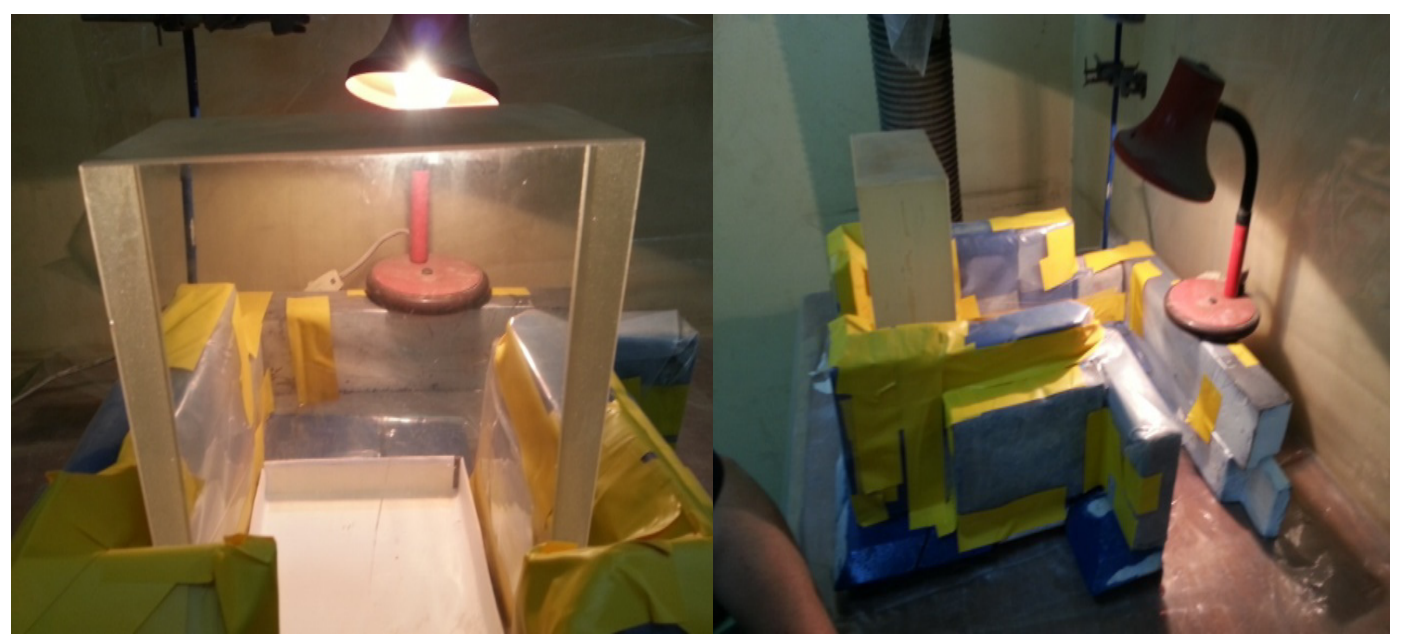

Fig. 1. Working area setup.

the decontamination in case any contamination should happen during the operation. A lamp and a mirror are installed inside the working area for good vision during the operation. The capsule used for conditioning is placed inside the working area and in the case of a capsule with two open ends, one end should be welded and checked first before use in conditioning.

The capsules should be manufactured from AISI 304 stainless steel welded tubes, 3/4 external diameter, 3-mm wall thickness; the capsule length is $110 \mathrm{~mm}$. Larger capsules may be used for special sources. The capsule is closed on both sides by $3-\mathrm{mm}$ stainless steel plates. Rods must be avoided as raw material due to inherent defects which could lead to leaks during storage. The capsules and lids must be free of any dirt dust, grease or oil - before welding. They should preferably be cleaned in a 10-min ultrasonic bath with water solution of $5 \%$ of neutral detergent after machining. Immediately before welding they must be cleaned with acetone.

\section{Source characterization}

According to equation (1), for radium sources and at a distance of $0.9 \mathrm{~m}$ from the capsule, the dose rate in $\mathrm{mR} / \mathrm{h}$ is equal to the activity of the source (for example, $100 \mathrm{mR} / \mathrm{h}$ will be equal to $100 \mathrm{mCi} \mathrm{Ra}-226)$ :

$$
\mathrm{H}_{0}=\Gamma \cdot \mathrm{A} / \mathrm{d}^{2}
$$

where $\Gamma$ is the ambient dose equivalent rate produced at $0.9 \mathrm{~m}$ by the Ra-226 source, expressed in $\mathrm{mR} \cdot \mathrm{m}^{2} / \mathrm{h} . \mathrm{mCi}$ (for $\mathrm{Ra}-226=0.81)$, A is the activity of the source, in $\mathrm{mCi}$.

$$
\begin{aligned}
& \mathrm{H}_{0}=0.81 \frac{\mathrm{mR} \cdot \mathrm{m}^{2}}{\mathrm{~h} \cdot \mathrm{mCi}} \times \frac{\mathrm{A} \_\mathrm{mCi}}{(0.9)^{2} \mathrm{~m}^{2}} \\
& \mathrm{H}_{0}=0.81 \frac{\mathrm{mR} \cdot \mathrm{m}^{2}}{\mathrm{~h} \cdot \mathrm{mCi}} \times \frac{\mathrm{A} \_\mathrm{mCi}}{0.81 \mathrm{~m}^{2}} \\
& \mathrm{H}_{0}=\text { A. }
\end{aligned}
$$

The equipment used during the real operations measures the dose rates in $\mu \mathrm{Sv} / \mathrm{h}$, and according to equation (1) this dose

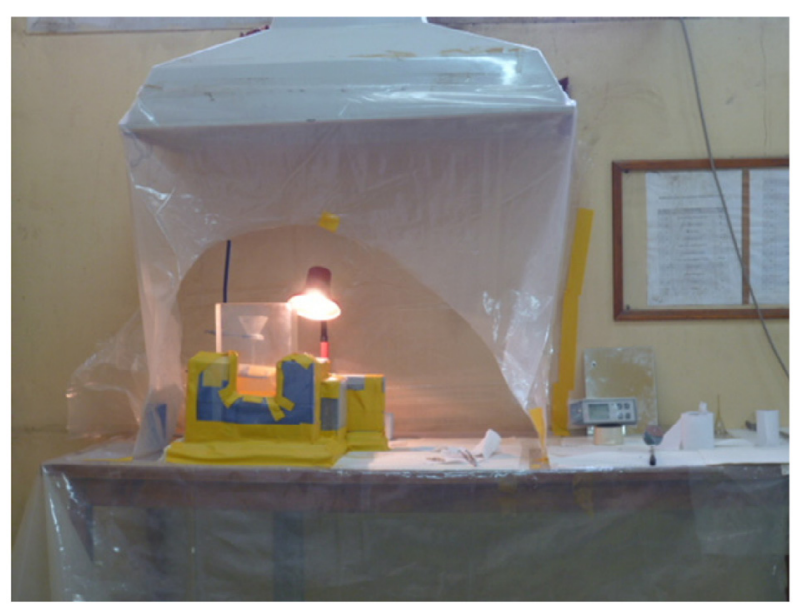

Fig. 2. Source characterization.

rate must be converted into $\mathrm{mR} / \mathrm{h}$, divided by 10 , because: $1 \mu \mathrm{Sv} / \mathrm{h}=100 \mu \mathrm{R} / \mathrm{h}, 1 \mu \mathrm{Sv} / \mathrm{h}=0.1 \mathrm{mR} / \mathrm{h}$. This calculation is only an estimation. We cannot say that it is the exact activity value for the radioactive sources, but for the management of disused radioactive sources it is considered adequate. This calculation is used very frequently, not only for radium. Normally a radioactive source is considered as a point source when its dimensions are around 10 times less than the distance between the source and the detector (the place where we are measuring the dose rates) (Blizard et al., 1968).

As seen in Figure 2, the lead cubes are prepared in such a manner as to protect the workers from the radiation of Ra-226 sources in the tray during the measurements for characterization. Before starting, the background radiation is measured to be subtracted from the measured source dose rates. The first $\mathrm{Ra}-226$ source is transferred to the capsule and the dose rate at $0.9 \mathrm{~m}$ is measured, the background is subtracted and the final dose rate (which equals the activity) is calculated. The second Ra-226 source is transferred to the capsule and the dose rate is measured again at the same distance. From the first and second readings, the dose rate or activity of the second source is calculated. The measurements are continued until the maximum 


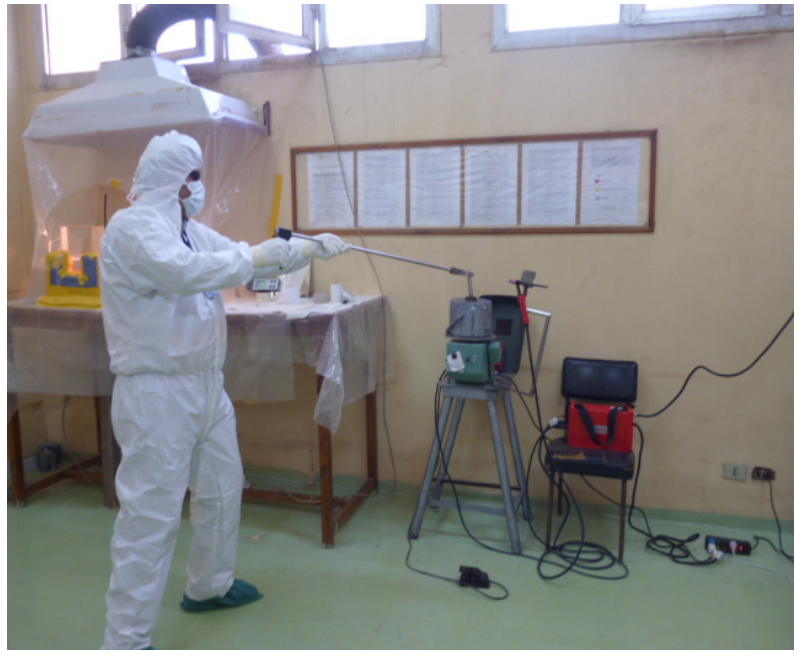

Fig. 3. Transferring the capsule to the welding area.

Ra-226 activity of $100-120 \mathrm{mCi}$ is reached. After that the capsule is transferred to another prepared area for welding.

\section{Welding the capsule}

After loading the capsule with the maximum Ra-226 activity $(100 \mathrm{mCi})$, it is closed with its cap and fitted smoothly with a light tool. The capsule is then transferred for welding to another prepared area using a long tong (Fig. 3). The capsule is placed in a shielding container to protect the welder and fix the capsule during welding. The center hole of this shield is reserved for a large capsule and another adaptor shield is necessary for standard capsules. The lid is welded by a fusion welding process using a tungsten inert gas (TIG) welding machine with high voltage (direct current, negative electrode between 30 and $50 \mathrm{~A}$, and argon gas with a flow of $8-10 \mathrm{~L} / \mathrm{min}$ ). Before starting welding, two welding spots at an angular distance of $120^{\circ}$ from each other for the capsule must be taken first to insure fitting of the cap during the welding process. The welding must begin at an angular distance of $120^{\circ}$ from the second welding spot and should be done in a single circumferential step spanning a $380^{\circ}$ angle, which means a $20^{\circ}$ overlap. The welding time must be approximately 25 seconds for standard capsules and 40 sconds for large capsules. The welder should use a helmet to protect his eyes and use a stand to keep his hand steady while welding the capsule (Fig. 4). After welding, the capsule must be allowed to cool naturally to avoid cracks and material brittleness.

\section{Capsule leakage test (bubble test)}

After welding the capsule, it must be examined for leakage. It is based on the standard ISO 9978 (ISO, 1992). To perform the leakage test (bubble test), a leak test area is set up as in Figure 5. This area contains a suitable clean glass pressure chamber filled with ethylene glycol. The chamber is attached to a vacuum pump and vacuum meter to control the pressure during the test. Lead bricks are used for shielding and a mirror is used behind the chamber for safe observation of the bubbles. The capsule to be tested is transferred to the pressure chamber using a long tong. The capsule must be submerged in at least $5 \mathrm{~cm}$ of glycol. After reducing the chamber's absolute pressure to $25 \mathrm{kPa}(0.25 \mathrm{~atm})$ the capsule is observed for bubbles for $1 \mathrm{~min}$. The capsule is considered approved if no bubbles are observed in the glycol. If any bubbles are observed, the capsule must go back to the welding area to be re-welded and re-checked again for leakage. If the capsule fails the bubble test for the second time, the capsule itself must be transferred and contained in a larger capsule (a large capsule can hold up to three standard capsules) which will be prepared for welding and checked for leakage. If the capsule is approved in the leakage test, it is transferred to one of the positions in the lead shield cask (the central hole is reserved for large capsules and the remaining holes (normally 7-9 holes) are for standard capsules. A diagrammatic drawing illustrating the lead shield for storage of conditioned Ra-226 sources as well as the standard and large capsules is shown in Figures 6 and 7.

\section{Packaging the conditioned Ra-226 sources}

When the lead shield is totally filled with the conditioned capsules, its surface dose rate may reach $20 \mathrm{mSv} / \mathrm{h}$ (equivalent to maximum Ra-226 activity of $5405 \mathrm{mCi}$ or $5400 \mathrm{mg}$ Ra-226 per shield) which is not a permissible limit for transportation or storage. To reduce this dose rate to the permissible limit $(2000 \mathrm{mR} / \mathrm{h})$ ? , a new package must be prepared prior to the conditioning process. A concrete shield of a $200 \mathrm{~L}$ metal drum lined with a pre-calculated thickness of concrete is prepared as shown in Figure 8. After loading these packages with the conditioned Ra-226 spent sources, they are transferred to the longterm storage at the same site. Portland cement, dry sand, water, a mold, two hooks and two protection bars are used for package preparation. The concrete molding should be prepared according to the following ratio per weight: $1: 1.2$ : $2: 0.5$ (cement : sand : gravel : water). The internal concrete lining is prepared in two steps: the base and lateral wall. The drum's external surface and the mold's top end must be protected with plastic sheets before the concrete pouring. Concrete is prepared by mixing cement, sand and gravel for 10 min then water is added and mixed for $10 \mathrm{~min}$ more. The base is prepared by marking the drum's internal wall at the mold's bottom end level and pouring concrete up to the mark. Then, we lay the mold on the fresh concrete's top surface and let the concrete cure for two weeks. The drum wall is prepared by introducing the cone between the drum and mold and pouring concrete from different sides. The concrete pouring should be done in steps using the concrete vibrator periodically to remove air bubbles. Then introduce the hooks immediately after the pouring and let the concrete cure for at least six hours.

\section{Capsule information form}

Prior to the conditioning operation, a data sheet form as in Tables 1-3, must be prepared to document information about the conditioned Ra-226 sources, the capsule, the lead shield 

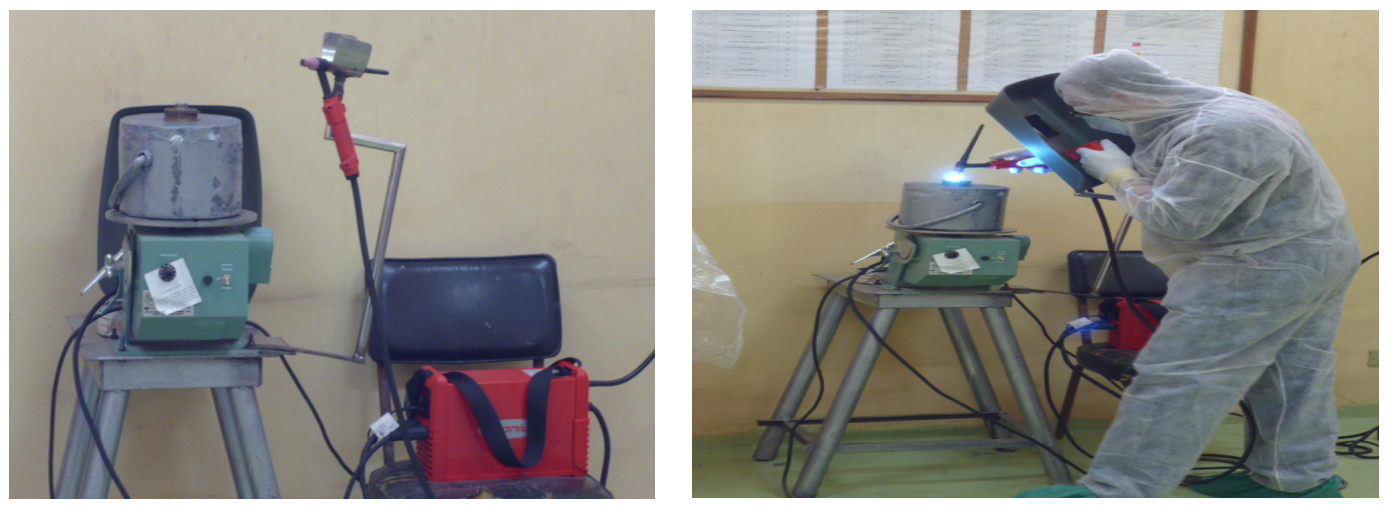

Fig. 4. Welding the capsule.
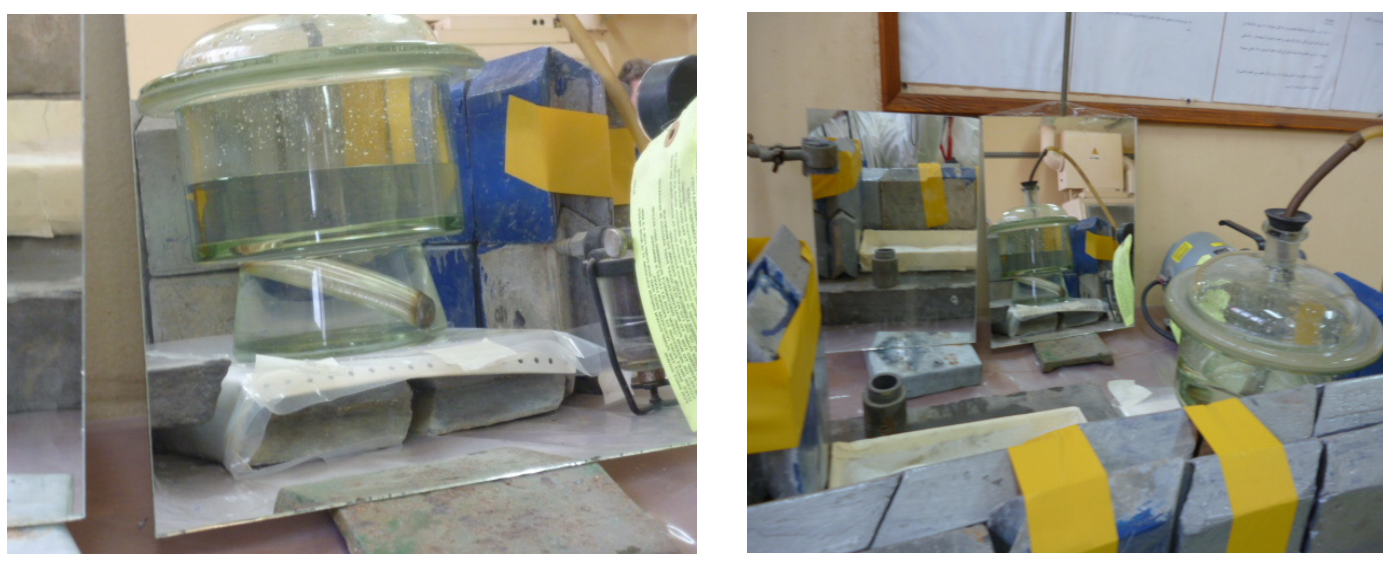

Fig. 5. Capsule leakage test.
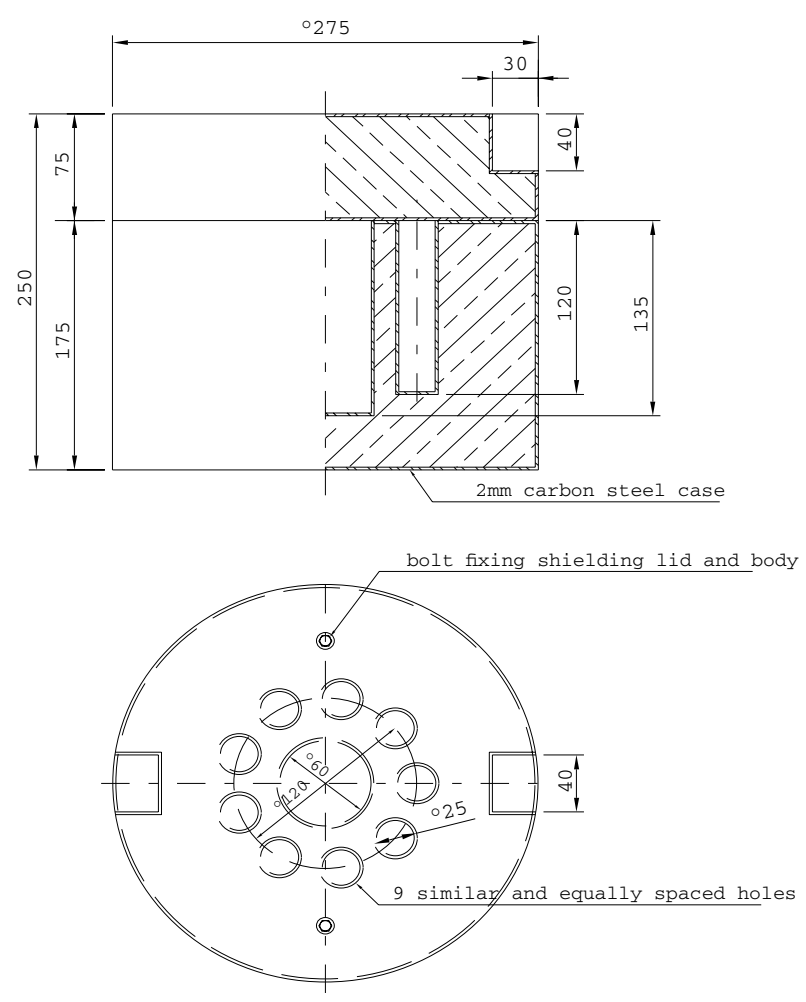

Fig. 6. Lead shield cask.

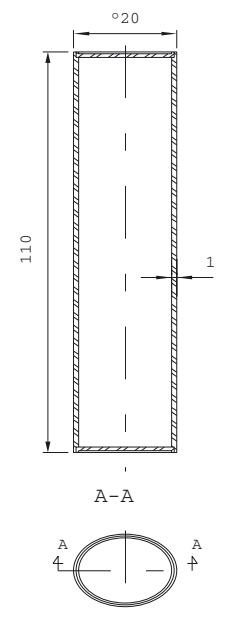

Standard capsule

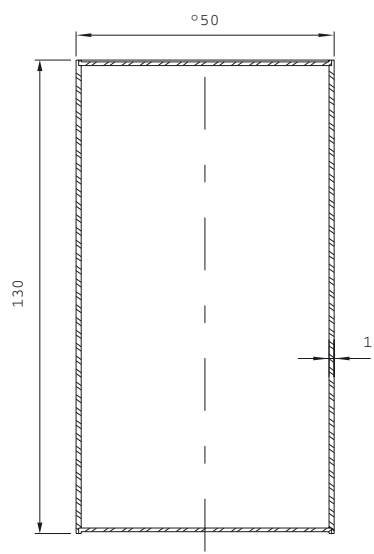

$\mathrm{B}-\mathrm{B}$

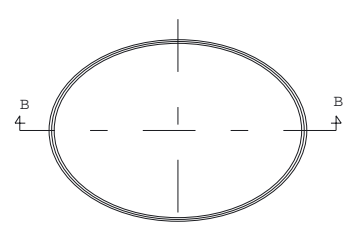

Large capsule

Fig. 7. Stainless steel capsules. 

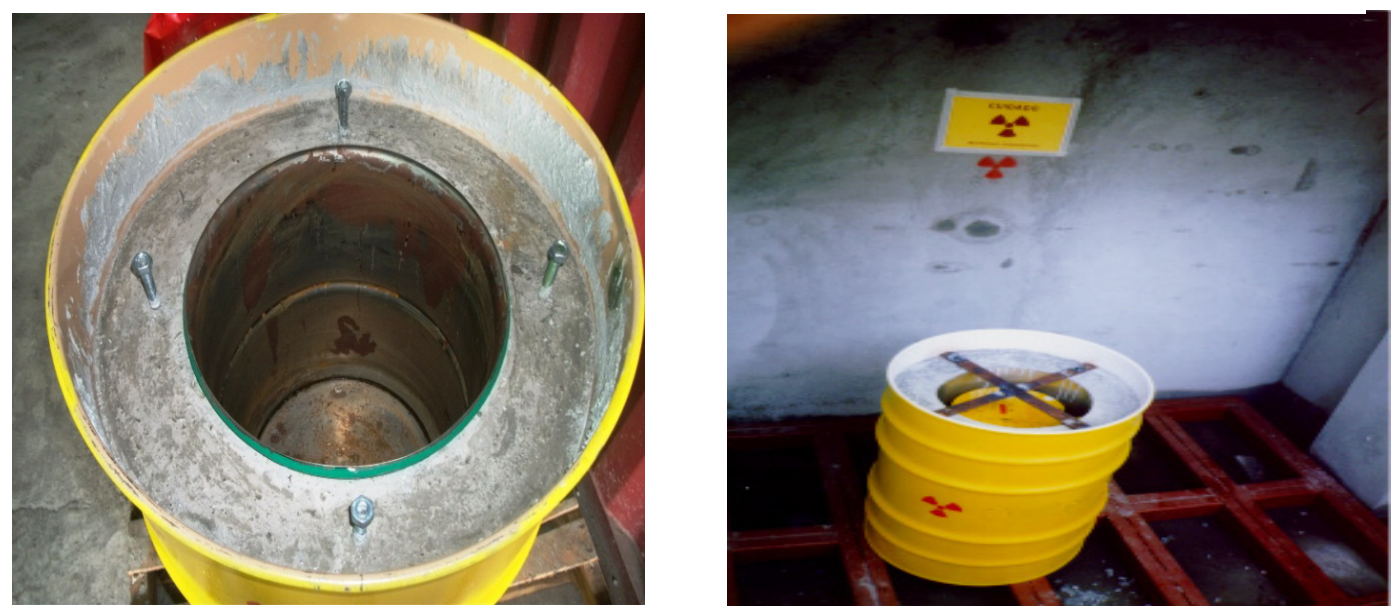

Fig. 8. Package for Ra-226 sources conditioning.

Table 1. Capsule information form.

\begin{tabular}{|c|c|c|c|c|c|}
\hline \multicolumn{5}{|c|}{ Capsule No. 1} & \multirow{2}{*}{$\begin{array}{c}\text { Background activity }=80 \mathrm{nSv} / \mathrm{h} \\
\text { Estimated activity } \\
\text { of the individual } \\
\text { source }(\mathrm{mCi})\end{array}$} \\
\hline $\begin{array}{l}\text { Original } \\
\text { storage } \\
\text { container }\end{array}$ & $\begin{array}{l}\text { Type } \\
\text { of } \\
\text { source }\end{array}$ & $\begin{array}{c}\text { Dose rate at } 0.9 \mathrm{~cm} \\
\text { from the capsule } \\
(\mu \mathrm{Sv} / \mathrm{h})\end{array}$ & $\begin{array}{l}\text { Dose rate at } 0.9 \mathrm{~cm} \\
\text { from the capsule } \\
(\mathrm{mR} / \mathrm{h})\end{array}$ & $\begin{array}{l}\text { Estimated total } \\
\text { activity in the } \\
\text { capsule (mCi) }\end{array}$ & \\
\hline Number 1 & Needle $2 \mathrm{~cm}$ & 21 & 2.1 & 2.1 & 2.1 \\
\hline Number 1 & Needle $2 \mathrm{~cm}$ & 43 & 4.3 & 4.3 & 2.2 \\
\hline Number 1 & Needle $3 \mathrm{~cm}$ & 50 & 5.0 & 5.0 & 0.7 \\
\hline Number 1 & Needle $4 \mathrm{~cm}$ & 59 & 5.9 & 5.9 & 0.9 \\
\hline Number 1 & Needle $2 \mathrm{~cm}$ & 70 & 7.0 & 7.0 & 1.1 \\
\hline Number 1 & Needle $3 \mathrm{~cm}$ & 81 & 8.1 & 8.1 & 1.1 \\
\hline Number 1 & Needle $3 \mathrm{~cm}$ & 90 & 9.0 & 9.0 & 0.9 \\
\hline Number 1 & Needle $4 \mathrm{~cm}$ & 111 & 11.1 & 11.1 & 2.1 \\
\hline Number 1 & Needle $3 \mathrm{~cm}$ & 125 & 12.5 & 12.5 & 1.4 \\
\hline Number 1 & Needle $4 \mathrm{~cm}$ & 145 & 14.5 & 14.5 & 2.0 \\
\hline Number 1 & Needle $3 \mathrm{~cm}$ & 166 & 16.6 & 16.6 & 2.1 \\
\hline Number 1 & Needle $3 \mathrm{~cm}$ & 186 & 18.6 & 18.6 & 2 \\
\hline
\end{tabular}

Table 2. Shielding information form.

\begin{tabular}{|c|c|c|c|c|c|}
\hline \multirow{2}{*}{$\begin{array}{c}\text { hielding } \\
\text { No }\end{array}$} & \multirow{2}{*}{$\begin{array}{c}\text { Capsule } \\
\text { No }\end{array}$} & \multirow{2}{*}{$\begin{array}{l}\text { Capsule } \\
\text { position }\end{array}$} & \multicolumn{2}{|c|}{ Activity } & \multirow{2}{*}{$\begin{array}{l}\text { Number } \\
\text { of sources }\end{array}$} \\
\hline & & & $\mathbf{m C i}$ & mg & \\
\hline \multirow{3}{*}{ EGY-1 } & 1 & 1 & 18.6 & 18.6 & 12 \\
\hline & & & & & \\
\hline & & & TOTAI & & \\
\hline
\end{tabular}

Table 3. Package information form.

\begin{tabular}{cccc}
\hline $\begin{array}{c}\text { Package } \\
\text { number }\end{array}$ & $\begin{array}{c}\text { Shielding } \\
\text { number }\end{array}$ & $\begin{array}{c}\text { Lead shield dose } \\
\text { rate } \mathbf{m R} / \mathbf{h})\end{array}$ & $\begin{array}{c}\text { Package dose } \\
\text { rate }(\mathbf{m R} / \mathbf{h})\end{array}$ \\
1 & EGY-1 & & Surface $\mathbf{1 ~ m ~ d i s t a n c e ~}$ \\
\hline
\end{tabular}

and the package such as the dose rate of the capsule during the conditioning process, final dose rate of the capsule, activities of Ra-226 sources, number of sources in the capsule, total activity in the capsule, capsule number, capsule position, lead shield dose rate and package dose rate on the surface and at $1 \mathrm{~m}$ from the surface.

\section{Radiation protection measures during the conditioning of Ra226 sources}

In order to accomplish the radiation protection requirements, the following administrative measures should be undertaken.

\subsection{Area description}

The area where radium sources are being handled or manipulated is called the operational area. This area should be identified and separated into controlled and free areas. The controlled area is the area subject to special safety rules, in which the radioactive exposure conditions can lead to annual effective equivalent doses greater than $1 / 50$ of the primary limit for workers. Inside this area, the radiation protection supervisor will perform the applicable monitoring and control in order 


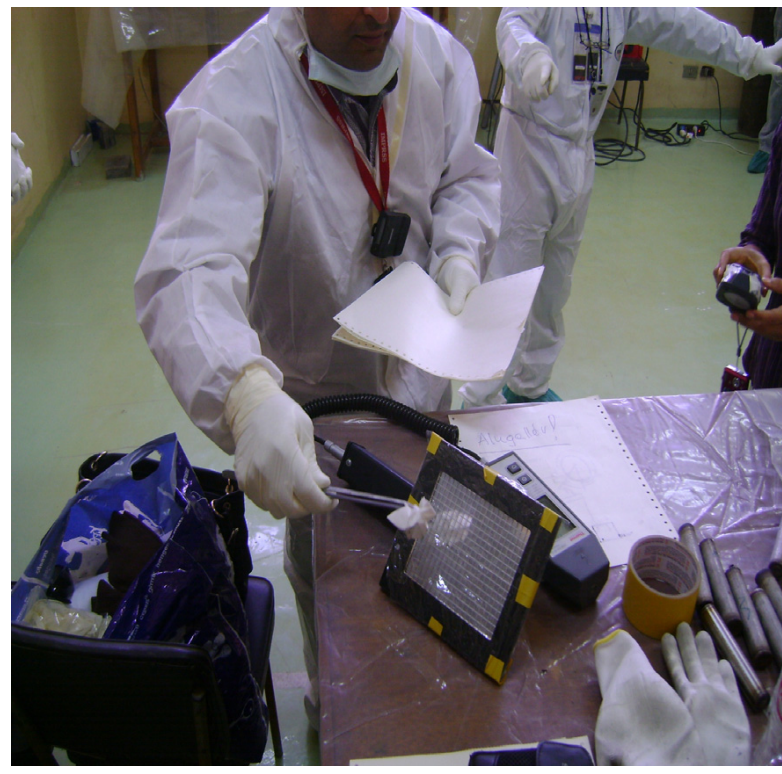

Fig. 9. Checking for contamination.

to guarantee safe working conditions and to avoid unnecessary irradiation exposure. The free area is the area exempt from any radiation safety rules, in which the annual effective equivalent doses are smaller than the primary limit for the general public. This is usually the area surrounding the controlled areas, where sources in their original containers are transported from the storage place to the conditioning room.

\subsection{Access to the operational area}

All the people entering the operational area should wear an individual dosimeter, overall and overshoes. Access should be allowed only by permission of the radiation protection supervisor. The radiation doses received by the persons during the work inside the controlled area should be consistent with the Basic Safety Standards (BSS).

\subsection{Minimum radiological protection requirements}

The place where the conditioning operation will be done should have at least the following radiation protection infrastructure: a hood with an air exhausting system with a minimum negative pressure of 5 mbar; a filtration system for the environmental air; a washbasin and emergency showers; laboratory benches with an impermeable surface; physical barriers to avoid access by unauthorized persons.

\subsection{Radiation protection equipment}

During the conditioning process, radiation protection equipment was used; a portable dose rate meter with a telescopic arm, Thermo FH 40; a portable surface contamination scintillation monitor, Thermo Contamat FH 1100; two tongs for capsule manipulation, 50 and $100 \mathrm{~cm}$ long; two 25-cm-long

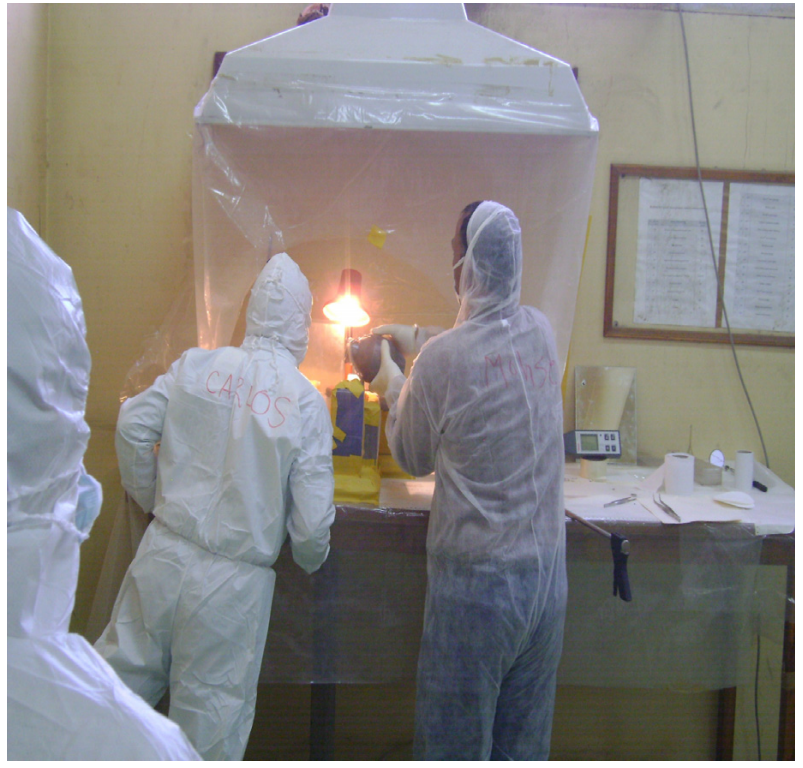

Fig. 10. Transfer the sources to the working area.

tongs, one curved and one straight; two 20-cm-long tweezers; two lead shields for holding one capsule, one for capsule welding and one for capsule transfer; two leaded glasses; two small lead pots for source segregation; three mirrors; plastic foils for tools and equipment wrapping; leaded glasses; lead bricks.

\subsection{Individual safety equipment and consumable material}

Workers were wearing their protective clothes and materials; gloves (surgical, rubber and heavy duty); overshoes; chest, finger and forehead dosimeters (film dosimeter or TLD); plastic foils; filter paper for the dry wipe test; absorbent paper.

\subsection{Verification of the contamination}

Source leakage prior to the conditioning operation should be verified first. Source leakage can be verified by direct measurements or the dry wipe method (Fig. 9). For direct measurements, we check the local background; put the probe as close as possible to the surface to be monitored (avoiding direct contact to prevent contamination of the probe); record the contamination measurement and subtract the background; and be sure that the measurement is not affected by other radiation fields. For the dry wipe test, we use a filter paper swab; choose a $10 \mathrm{~cm} \times 10 \mathrm{~cm}$ surface; thoroughly rub the chosen surface with the swab, always in the same direction; check the radiation background with the contamination monitor; measure the swab and subtract the background. The working area background should be detected and subtracted from source measured doses. After transferring the sources to the working area, the container should be examined for any remaining sources of contamination and physical characterization of sources should take place (dimensions and types): Figures 10-12. 


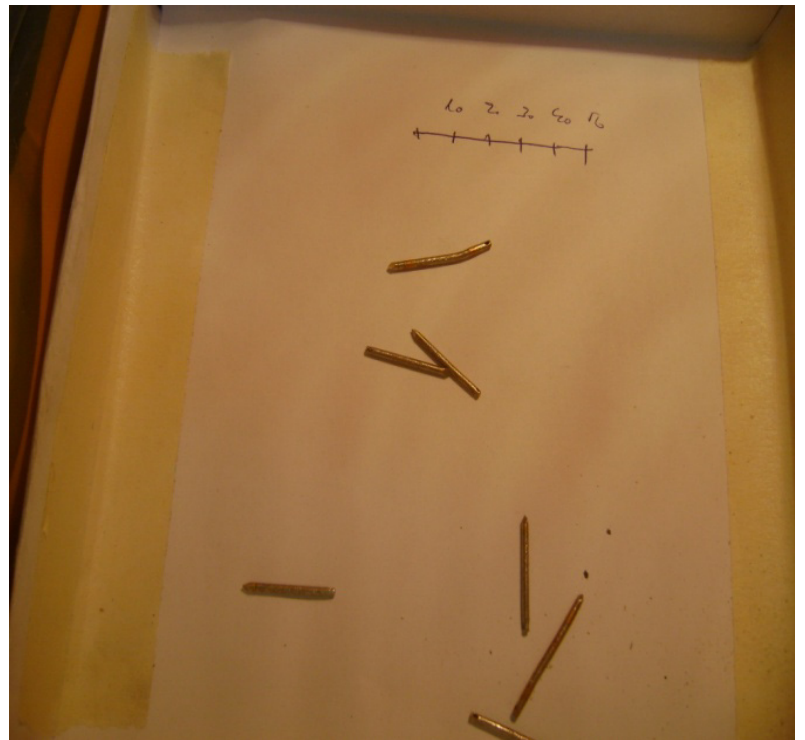

Fig. 11. Physical characterization of Ra-226 sources.

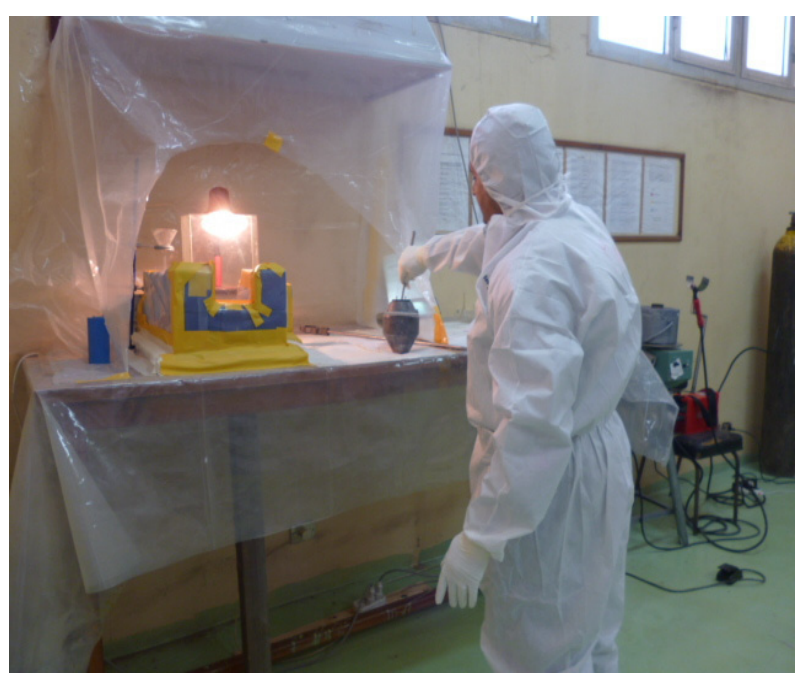

Fig. 12. Checking sources container for contamination.

\subsection{Contamination management}

Although the contamination level through this work was (0) $\mathrm{Bq} / \mathrm{cm}$ (contamination limits up to $0.4 \mathrm{~Bq} / \mathrm{cm}$ ), decontamination plans were previously prepared to control any contamination of the environment or personnel with Ra-226 during the conditioning process as follows (IAEA, 1979).

\subsection{Clothing}

Workers should wear a clean pair of gloves and carefully remove all contaminated clothing in such a way as to prevent a further spread of contamination, especially to the skin. Remove clothing inside out to contain the contamination. The contaminated clothing should be sealed inside plastic bags labeled as "radioactive material" and full information on the package of the name and phone number of the owner of the clothing; the radioisotope involved and the amount of activity (cpm, uCi, mR/hr), if known; and the date of the contamination incident. After removal of contaminated clothing, exposed skin areas should be carefully monitored and ensure that the hands are also monitored. If skin contamination is detected, we should follow the next section.

\subsection{Skin and hair}

The contaminated surface should be thoroughly washed with lukewarm or tepid water and soap for 2-3 minutes and monitored. If hair contamination is not lowered to acceptable levels after washing several times, the head should be shaved and apply skin decontamination methods. The contaminated surface should be brushed with a soft brush, washed for 2 minutes, rinsed 3 times and then monitored.

\subsection{Eyes, ears, nose and mouth}

For contamination of the eyes, ears, nose or mouth, roll back the eyelid as far as possible, and flush with large amounts of water. If isotonic irrigants are available (sol. 9\% $\mathrm{NaCl}$ ), apply to the eye continually and flush with large amounts of water. Apply the same method for the ears, nose and throat. Further decontamination should be done under medical supervision.

\subsection{Other surfaces}

Typical methods used for decontamination include wiping, scrubbing, flushing and/or soaking. We should start with the method which will create the least amount of radioactive waste and progress, if needed, to the more involved decontamination methods. Surfaces should be frequently monitored during decontamination with either portable survey instruments or wipe tests to determine the effectiveness of the procedures being used. The final surveys must consist of wipe test surveys to ensure that no removable contamination in excess of the limits exists. Items and surfaces which cannot be successfully decontaminated must be identified and controlled as radioactive material. Upon completion of decontamination procedures, workers should remove their gloves and wash their hands thoroughly. Monitor hands, body, overalls, etc. for radioactive contamination.

\subsection{Dose received by operators}

The total dose received within a total working time of 3 hours by 8 operators ranged from 10 to $48.8 \mu \mathrm{Sv}$ as shown in Table 4.

\section{Conclusion}

This paper is designed to provide information required for the waste management team to carry out the conditioning operation and transfer know-how about the conditioning of disused 
Table 4. Dose received by 8 operators.

\begin{tabular}{cc}
\hline Total dose received $(\boldsymbol{\mu S v})$ & Number of operator \\
\hline $2-5$ & - \\
$5-10$ & 1 \\
$10-20$ & 1 \\
$20-30$ & 2 \\
$30-40$ & 3 \\
$40-50$ & 1 \\
\hline
\end{tabular}

Ra-226 radioactive sealed sources. According to previous experience there are several points of a general nature that may provide good hints for a successful operation. These are as follows.

- Great effort should be made during the preparatory work. It is advisable, for instance, to review all the radium sources prior to the conditioning operation. Preferably this should be done by a member of the team who will carry out the conditioning operation (e.g. the team leader).

- It is important to take necessary action and follow it up to guarantee the equipment arrival on time for the operation.

- Frequent (continuous) checks for contamination during the operation are strongly recommended.

Work that was not planned should not be carried out. It should only be carried out if all aspects are studied and all concerned have agreed to the approach and procedures. Deviation from the planned work should be considered given that safety and radiation protection requirements are adhered to.
- Any contamination caused due to the operation should be dealt with by the team who has carried out the operation. Any other contamination (previous) should be discussed and plans for its removal should be considered by the local staff.

- Should contamination occur, ventilation should be arranged such that it does not cause any further spread of contamination.

\section{References}

Blizard E.P., Foderaro A., Goussev N.G., Kovalev E.E., Alter J., Foderaro A. (1968) Engineering Compendium on Radiation Shielding, Chap. 6 (Extended Radiation Sources), pp. 363-416.

IAEA (1979) Manual on Decontamination of Surfaces, Safety Standards Series No. 48, IAEA, Vienna.

IAEA (1990) Regulations for the Safe Transport of Radioactive Material, Safety Series No. 6, Vienna (revised 1996).

IAEA (1996a) International Basic Safety Standards for Protection against Ionizing Radiation and for the Safety of Radiation Sources, Safety Series No. 115, Vienna, Austria.

IAEA (1996b) TECDOC-886, Conditioning and interim storage of spent radium sources.

ISO 9978 (1992) Radiation Protection-Sealed Radioactive SourcesLeakage test Method. 49 CFR 173, 469(a)(4)(ii).

Punnachaiya M., Sawangsri T., Wanabonges P., Pruantonsai P., Nunjan P., Phattanasub A., Ya-Anant N., Thiangtrongjit S. (2006). In: WM"06 Conference, February 26-March 2, 2006, Tucson AZ.

Cite this article as: M.A. Hasan, Y.T. Selim, Y.F. Lasheen, T. El-Zakla. Conditioning of disused Ra-226 radioactive sealed sources in Egypt. Radioprotection 49(3), 213-220 (2014). 